Tropical Journal of Pharmaceutical Research July 2019; 18 (7): 1427-1433

ISSN: 1596-5996 (print); 1596-9827 (electronic)

(C) Pharmacotherapy Group, Faculty of Pharmacy, University of Benin, Benin City, 300001 Nigeria.

\title{
Number of macrophages and transforming growth factor $\beta$ expression in Citrus limon L. Tlekung peel oil-treated traumatic ulcers in diabetic rats
}

\author{
Meircurius Dwi Condro Surboyo', Fatma Yasmin Mahdani ${ }^{1}$, Diah Savitri \\ Ernawati $^{1 *}$, Priyo Hadi ${ }^{1}$, Hening Tuti Hendarti ${ }^{1}$, Adiastuti Endah Parmadiati ${ }^{1}$, \\ Desiana Radithia ${ }^{1}$, Shiffin Devi Mardiyana ${ }^{2}$, Indi Mazaya Syarifah ${ }^{3}$ \\ ${ }^{1}$ Department of Oral Medicine. ${ }^{2}$ Oral Medicine Specialist Programme, ${ }^{3}$ Dental Surgery Student, Faculty of Dental Medicine, \\ Universitas Airlangga, Jalan Prof Dr Moestopo No. 47, Surabaya, Indonesia
}

${ }^{*}$ For correspondence: Email: diah-s-e@fkg.unair.ac.id

Sent for review: 21 March 2019

Revised accepted: 19 June 2019

\begin{abstract}
Purpose: To analyse the potential use of Citrus limon L Tlekung peel oil in the treatment of traumatic ulcers in diabetic rats based on number of macrophages and transforming growth factor $\beta$ (TGF- $\beta$ ) expression.

Method: Standard steam distillation was performed to produce Citrus limon $L$ peel oil with its components subsequently analysed by gas chromatography-mass spectrometry (GC-MS). Diabetes was induced with streptozotocin (STZ) via administration of a single $50 \mathrm{mg} / \mathrm{kg}$ dose. A traumatic ulcer was subsequently induced with a $5 \mathrm{~mm}$ burnisher heated for $30 \mathrm{~s}$ and applied without pressure for $1 \mathrm{~s}$ to the lower labial mucosa of the animals. Citrus limon L oil gel containing 3\% carboxyl methyl cellulose sodium was then topically administered to the traumatic ulcer for a period of three or five days. TGF- $\beta$ expression was analysed through immunohistochemical staining and the macrophage number calculated with haematoxylin-eosin stain.

Results: The major identified compounds in Citrus limon $L$ peel oil include fumaric (31.78 \%), dlimonene (17.38\%), z-citral (13.55\%), L-linalool (8.51\%), geraniol nerol (3.56\%), geraniol (2.94\%,), $\alpha$ terpineol $(1.25 \%)$ and $\gamma$-terpinene $(1.03 \%)$ together with other minor constituents. Treatment of traumatic ulcers with Citrus limon $L$ peel oil produced higher number of macrophages and TGF- $\beta$ expression $(p=0.000)$. Treatment over a period of five days also indicated higher expression of TGF- $\beta$ and number of macrophages compared to that lasting three days with Citrus limon $L$ peel oil $(p=0.000)$. Conclusion: Citrus limon $L$ peel oil stimulates TGF- $\beta$ expression and an increase of macrophage numbers in diabetic subjects during traumatic ulcer healing after three and seven days. Clinical application of Citrus limon $L$ peel oil constitutes a potential therapy in the treatment of traumatic ulcers in diabetic subjects.
\end{abstract}

Keywords: Citrus limon L peel oil, traumatic ulcer, diabetes, macrophage, transforming growth factor $\beta$

This is an Open Access article that uses a fund-ing model which does not charge readers or their institutions for access and distributed under the terms of the Creative Commons Attribution License (http://creativecommons.org/licenses/by/4.0) and the Budapest Open Access Initiative (http://www.budapestopenaccessinitiative.org/read), which permit unrestricted use, distribution, and reproduction in any medium, provided the original work is properly credited.

Tropical Journal of Pharmaceutical Research is indexed by Science Citation Index (SciSearch), Scopus, International Pharmaceutical Abstract, Chemical Abstracts, Embase, Index Copernicus, EBSCO, African Index Medicus, JournalSeek, Journal Citation Reports/Science Edition, Directory of Open Access Journals (DOAJ), African Journal Online, Bioline International, Open-J-Gate and Pharmacy Abstracts 


\section{INTRODUCTION}

Ulceration is one of the most common conditions affecting the oral cavity. Ulceration of the oral mucosa is referred to as an oral ulcer, characterized by loose epithelial layers extending from the stratum corneum to the basal membranes. The potential characteristics of oral ulcers include their being recurrent, persistent, solitary or multiple [1]. The majority of traumatic oral ulcerations are caused by factors including: mechanical, thermal and chemical. This type of ulcer will commonly heal within seven to ten days as the result of a keratinization process and epithelial cell regeneration in the oral mucosa [2].

Diabetics, in contrast to non-sufferers of the condition, will experience prolongation or even failure of the wound healing process. This situation is caused by certain complications experienced by diabetic patients, including: microangiopathy, neuropathy and immune cell dysfunction [3,4]. $74.8 \%$ of diabetics present such symptoms in their oral mucosa. Symptoms other than periodontal diseases comprise: oral candidiasis $(24 \%)$, traumatic ulcers $(16.4 \%)$, taste impairment (20\%), halitosis (16\%), burning mouth sensation (10\%) and melanin pigmentation (12.7\%) [5]. Individuals suffering from oral ulcers such as the traumatic variety complain of pain that impedes the mastication process, resulting in deficient nutritional intake [3].

The main purposes of oral ulcer therapy comprise pain reduction, prevention of secondary infection and accelerated healing. Currently, antiinflammatory drugs such as corticosteroid or those of the non-steroid (NSAID) variety are commonly used to treat traumatic ulcers [6]. However, corticosteroid is contraindicated for diabetics which raises another problem for which herbal medicine can be proposed as an alternative therapeutic agent [7].

Citrus limon L., or lemon, is a citrus fruit containing beneficial elements which is produced in large quantities exceeding 100 million tons per season in various regions of the world. The main components found in Citrus limon $L$ peel essential oil include: $d$-limonene, $\alpha$-and $\beta$ pinene. D-limonene has the ability to eliminate oxidative free radicals, namely reactive oxygen species (ROS), thereby protecting immune cells from oxidative damage [8]. $\alpha$ - and $\beta$-pinene also execute an antioxidant function because of their ability to inhibit the synthesis of nitric oxide (NO) which is also an oxidative free radical. $d$ limonene and $\alpha$ - and $\beta$-pinene can potentially inhibit the synthesis of $\mathrm{NO}$ and ROS, enhance cell immunity and restrict the capacity of proinflammatory cytokines to produce tumor necrosis factor $\alpha$ (TNF- $\alpha$ ), interleukin $1 \beta$ (IL-1 $\beta$ ) and interleukin 6 (IL-6) [9]. D-limonene is able to induce the synthesis of extracellular matrix component and collagen by upregulating TGF- $\beta$ signalling. The inhibition of pro-inflammatory cytokine production and upregulating of TGF- $\beta$ signalling is capable of promoting the ulcer healing process under diabetic conditions [10].

The purpose of this experiment was to analyse the potential for Citrus limon $L$ peel oil to act as a therapeutic agent during the treatment of traumatic ulcers in diabetic rats by observing TGF- $\beta$ expression and macrophage numbers after topical treatment lasting three and five days. These periods constitute the inflammation phase and the onset of the proliferation phase within the traumatic ulcer healing process [11].

\section{EXPERIMENTAL}

\section{Plant material}

The Citrus limon L. used constituted ripe yellow fruit supplied by the Subtropical Fruit Research Institute located in Tlekung Village, Junrejo Subdistrict, Batu City, East Java. Taxonomy was conducted at the Biology Unit of the Faculty of Science and Technology, Universitas Airlangga, Surabaya, Indonesia.

\section{Citrus limon peel oil}

Citrus limon $L$ peel oil was extracted from Citrus limon $L$. peel through a process of standard steam distillation performed at the Faculty of Pharmacy, Universitas Airlangga, Surabaya. The resulting oil was diluted with Tween 20 (P9416 Sigma, Sigma Aldrich) and corn oil at a ratio of $5: 2: 1$ to produce a concentration of $0.78 \%$ before being mixed with carboxyl methyl cellulose sodium $3 \%$ (CMC-Na $3 \%$ ) (C5678 Sigma, Sigma Aldrich) to form a gel.

\section{Chemical analysis of Citrus limon $L$ peel oil}

The Citrus limon $L$ peel oil $(1000 \mu \mathrm{l})$ was agitated with $1500 \mu \mathrm{l}$ dichloromethane (Merck, pure analysis or p.a.) to induce separation of the solvent layer was subsequently added twice to $1000 \mu \mathrm{l}$ dichloromethane before the mixed solvent layer extract was collected.

The components were then identified by GC-MS using a gas chromatograph, model 6890N (Agilent Technologies, Inc., Santa Clara, CA) equipped with a mass spectrometer detector 5973 inert MSD (Agilent Technologies, Inc., 
Santa Clara, CA) and J \& W Scientific column (J \& W Scientific, stationary phase; phenylmethylsiloxane $30 \mathrm{~m} \times 0.32 \mathrm{~mm}$; i.d. 0.25 $\mu \mathrm{m})$. The injector temperature was $290{ }^{\circ} \mathrm{C}$, while the carrier gas (helium) was delivered at a constant flow rate of $1.5 \mathrm{ml} / \mathrm{min}$. The initial oven temperature of the column was raised from 50 to $280{ }^{\circ} \mathrm{C}$ at a rate of $10{ }^{\circ} \mathrm{C} / \mathrm{min}$ and then maintained at $280^{\circ} \mathrm{C}$ for five minutes. The mass spectrometer detector conditions consisted of a capillary direct interface temperature of $290{ }^{\circ} \mathrm{C}$, an MS Source temperature of $230{ }^{\circ} \mathrm{C}$, an MS Quad temperature of $150^{\circ} \mathrm{C}$. ionization energy of $70 \mathrm{eV}$, mass range of $\mathrm{m} / \mathrm{z} 20-800$ a.m.u. and a scan rate of $1.4 \mathrm{scan} / \mathrm{s}$. The total flow was 104 $\mathrm{mL} / \mathrm{min}$; the column flow $1.5 \mathrm{~mL} / \mathrm{min}$ and the linear velocity $36.262 \mathrm{~cm} / \mathrm{sec}$. Constituent identification was based on a comparison of their mass spectra and retention time indices relating to authentic reference compounds stored in the Wiley version 7.0 library of mass spectral data.

\section{Animals}

Ethical approval was obtained from the Ethical Clearance Section of the Health Experiment Committee (KEPK), Faculty of Dental Medicine, Universitas Airlangga with registration no. 109/HRECC.FODM/VII/2018. The handling of animals adhered strictly to U.S. National Institute of Health Guidelines for the Care and Use of Laboratory Animals [12].

Two-month-old male Wistar rats, weighing 120 $160 \mathrm{~g}$, supplied by the Animal Laboratory of the Faculty of Medicine, Universitas Airlangga were used in the experiments. All subjects were housed in temperature-controlled $\left(27{ }^{\circ} \mathrm{C}\right)$ collective cages and artificially illuminated rooms on a 12-hour light/12-hour dark cycle. During the experiment all the subjects received pellets as their standard diet and free access to water.

\section{Diabetic and traumatic ulcer model}

Diabetes was induced with streptozotocin (S0130 Sigma, Sigma Aldrich) dissolved in 22.5 $\mathrm{mL}$ citrate buffer $\mathrm{pH} 4.5$ and administered intraperitoneally through a single dose of 50 $\mathrm{mg} /$ body weight. A diabetic condition was considered to exist when the fasting blood glucose $\geq 126 \mathrm{mg} / \mathrm{dL}$ as measured by a glucometer (Accu-chek, Roche Diabetes Care Inc.) 48 hours after induction [13].

Following confirmation of diabetes, a traumatic ulcer was produced on the lower labial mucosa of subjects, which had been anesthetized with ketamine, by one second of pressure-less contact using a $5 \mathrm{~mm}$ burnisher which had been previously heated for 30 seconds [14]. The presence of a traumatic ulcer, a lesion with the appearance of as yellow base with reddish edges, was confirmed 48 hours later. The ulcer was topically treated with Citrus limon $L$ peel oil once a day for three or five days. The control groups topically treated with CMC-Na $3 \%$.

\section{Macrophage and TGF- $\beta$ counting on traumatic ulcer}

After being topically treated for three or five days, all subjects were sacrificed by means of the inhalation of ether with the lower labial mucosa tissue subsequently being subjected to biopsy. The traumatic ulcer area of the lower labial mucosa tissue was subsequently subjected to immunohistochemical and histological examination. Immunohistochemistry staining was completed to determine the TGF- $\beta$ expression (TGF- $\beta$ anti-antibody monoclonal, Santa Cruz Biotechnology) using an indirect technique. The number of macrophages was calculated through histological examination involving haematoxylineosin staining. TGF- $\beta$ expression was quantified by counting the number of macrophages. Those macrophages expressing TGF- $\beta$ will appear with dark cytoplasm [15]. Analysis involved the use of a light microscope (Nikon H600L microscope; Nikon, Japan) at a magnification of $200 \times$ (DS Fi2 300MP digital camera; Nikon, Japan, software digital imaging by Nikon Image System, Nikon, Japan).

\section{Statistical analysis}

Data was presented as mean \pm standard deviation (SD) and analysed using a Statistical Package for the Social Sciences (SPSS) 24.0 version for Windows (IBM Corporation, Illinois, Chicago, United State). An independent t-test ( $p$ $<0.05$ ) was performed based on a normality test $(p>0$. 05) prior to conducting a data homogeneity $(p>0.05)$ test.

\section{RESULTS}

In total, 52 components were identified in Citrus limon $L$ peel oil, the major ones being fumaric acid $(31.78 \%)$, D-limonene (17.38\%) and zcitral $(13.55 \%)$. Other components included: Llinalool, benzene, geraniol nerol, geraniol, $\alpha-$ terpineol and $y$-terpinene, constituting 8.51, 6.43, $3.56,2.94,1.25$ and $1.03 \%$, respectively (see Table 1).

The number of macrophages was significantly different in the rats treated with Citrus limon $L$ peel oil compared to those in the control group (see Figure 1). After treatment with Citrus limon $L$ 
peel oil for three days $(14.67 \pm 1.37)$ and five days $(19.67 \pm 1.5)$ the number of macrophages was significantly higher than that in the control group $(7.67 \pm 0.82 ; 11.67 \pm 1.21)(p=0.000)$. The number of macrophages following five days of treatment with Citrus limon $L$ peel oil was significantly higher than that after three days $(p=$ 0.000) (Figure 2).

TGF- $\beta$ expression also showed significant differences between the group treated with Citrus limon $L$ peel oil and the control group (Figure 3 ). TGF- $\beta$ expression after treatment with Citrus limon $L$ peel oil for three days $(10.67 \pm 1.5)$ and five days $(13.5 \pm 2.43)$ was significantly higher than in the control group $(6.83 \pm 1.6 ; 9.83 \pm 2.04)$ $(p=0.000)$. Treatment with Citrus limon $L$ peel oil for five days also resulted in significantly higher TGF- $\beta$ expression than that lasting for three days $(p=0.000)$ (Figure 4$)$.

Table 1: Identified components of Citrus limon $L$ peel oil using GC-MS

\begin{tabular}{|c|c|c|}
\hline Component & RT & Area (\%) \\
\hline Fumaric acid & 8.45 & 31.784 \\
\hline D-limonene & 12.80 & 17.384 \\
\hline Z-Citral & 12.33 & 13.554 \\
\hline L-Linalool & 9.93 & 8.512 \\
\hline Benzene & 8.32 & 6.439 \\
\hline Geraniol Nerol & 12.54 & 3.567 \\
\hline Geraniol & 22.57 & 2.947 \\
\hline$\alpha$-Terpineol & 11.48 & 1.256 \\
\hline y-terpinene & 9.04 & 1.038 \\
\hline$\beta$-pinene & 7.09 & 0.310 \\
\hline Citral a & 10.70 & 0.242 \\
\hline$\beta$-pinene & 7.55 & 0.239 \\
\hline a-pinene & 5.92 & 0.155 \\
\hline Others & & 12.573 \\
\hline
\end{tabular}

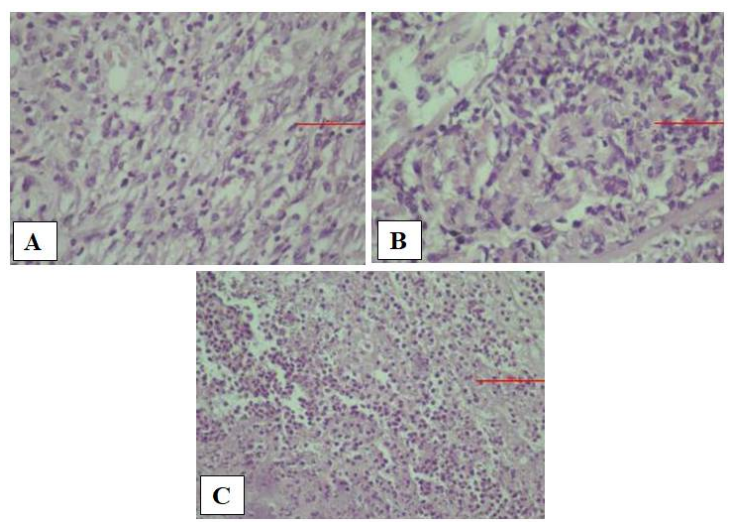

Figure 1: The number of macrophages within the traumatic ulcer area following haematoxylin-eosin staining. (A) control group; (B) Treatment with Citrus limon $L$ peel oil for three days; (C) Treatment with Citrus limon $L$ peel oil for five days at $200 x$ magnification

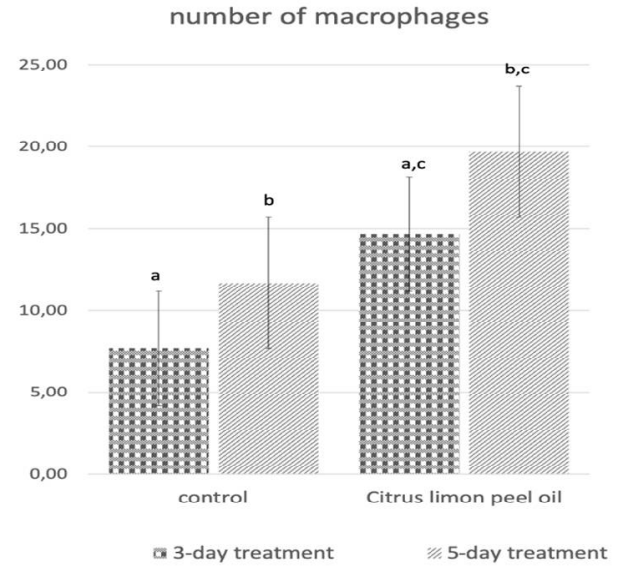

Figure 2: Number of macrophages after treatment of diabetes-related traumatic ulcers with Citrus limon $L$ peel oil. The same letters above the standard deviation line means a significant difference in the number of macrophages. The significant difference at $p<0.05$

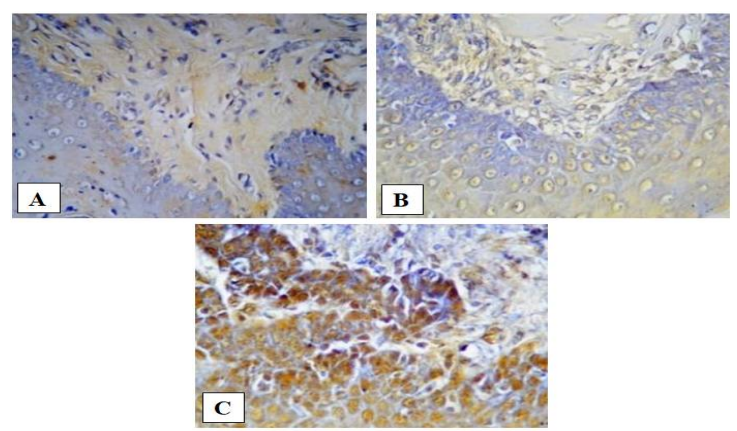

Figure 3: TGF- $\beta$ expression in macrophages identified by means of immunohistochemistry staining. (A) control group; (B) 3-day treatment with Citrus limon $L$ peel oil group; (C) 5-day treatment with Citrus limon $L$ peel oil group All groups subjected to $200 x$ magnification

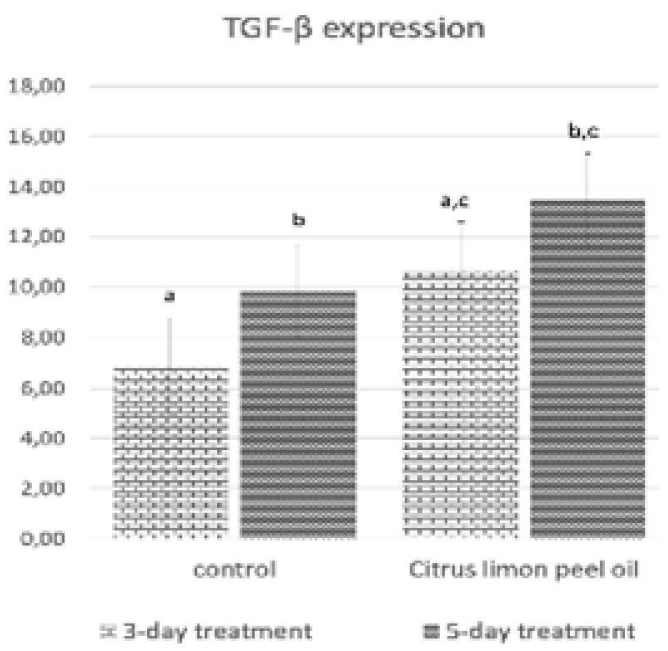

Figure 4: TGF- $\beta$ expression in traumatic ulcer with diabetes after treatment with Citrus limon $L$ peel oil. The same letters above the standard deviation line means a significant difference in the number of macrophages; significant difference at $p<0.05$

Trop J Pharm Res, July 2019; 18(7): 1430 


\section{DISCUSSION}

The components of Citrus limon $L$ peel oil used in this study and derived from Tlekung, included: fumarate acid $(31.78 \%)$, d-limonene $(17.38 \%)$, z-citral (13.55\%), L-Linalool (8.51\%, benzene (6.43\%), a-pinene $0.15 \%, \beta$-pinene $0.23 \%$ and others at a concentration of $0.1-3.5 \%$. This composition differed slightly from that of Citrus limon $L$ peel oil which has been the focus of studies conducted outside Indonesia. In general, these have shown limonene to be present at the highest concentration of more than $30 \%$, while that of fumarate acid was generally no more than $10 \%$ [16]. Limonene, $\alpha$-pinene and $\beta$-pinene are all active ingredients of Citrus limon peel oil. The varying concentrations of Cirus limon $L$ peel oil present in natural samples depend on geographical distribution and environmental conditions such as temperature, humidity, rainfall, air pressure, altitude, water precipitation and hours of daylight [17].

The healing process of traumatic ulcers is a complex pathophysiological one involving cell proliferation, migration, synthesis and deposition of extracellular matrix proteins, in addition to tissue remodelling. There are several phases in the ulcer healing process, namely: haemostasis, inflammation, proliferation, and remodelling [18].

Macrophages, which have two forms, M1 and M2, constitute tissue monocytes resulting from differentiation and are markers of chronic inflammation. They play an important role in intensifying the inflammatory response and tissue debridement. M1 macrophages execute the role of causing chronic inflammation by producing granulation tissue and releasing proinflammatory cytokines. M2 macrophages actuate the proliferation phase through the release of growth factors, one of them is transforming growth factor $\beta$ (TGF- $\beta$ ). With the assistance of platelet-released vascular endothelial growth factor (VEGF) and TGF- $\beta$, endothelial cells proliferate with the result that angiogenesis ensues. This process is essential for the synthesis, deposition and organization of a new extracellular matrix (ECM) and facilitates ulcer closure [19].

Under diabetic conditions, the inflammatory phase will tend to be more protracted and persistent, pro-inflammatory cytokines are continuously released and the number of antiinflammatory cytokines released decreases resulting in delayed healing $[20,21]$. Diabetes appears to modulate the inflammatory phase by inhibiting the recruitment of polymorphonuclear leukocytes, or PMNs, such as neutrophils, reducing the leukocyte-mediated bactericidal activity and increasing inflammatory cytokines production by modulating M1 macrophages. Diabetes also hinders the proliferative phase of wound healing, during which the wound is closed, by reducing the presence of production growth factors, such as TGF- $\beta$, EGF, VEGF and FGF. This, in turn, negatively affects the recruitment and proliferation of fibroblasts and vascular cells, collagen deposition and angiogenesis [22]

The increased number of macrophages was higher in the essential oil treatment group, both for subjects following 3-day and 5-day treatment regimes. The amount of cyclopentane or fumarate acid was highest in Citrus limon $L$ peel oil and d-limonene which can reduce the production of oxygen radicals such as reactive oxygen species (ROS) and nitrogen radicals such as reactive nitrogen species (RNS) and nitrogen nitric oxide (NO) which protect immune cells from oxidative damage. At the cellular level, NO produces a variable effect on leukocyte cell function, including apoptosis and stimulation of cytoplasmic motility in macrophages, modulation of neutrophil adhesion and differential regulation of cytokine synthesis by leukocytes. By decreasing NO production, the cytoplasmic apoptosis and motility of macrophages do not occur, thereby facilitating their proliferation [23].

The results showed that TGF- $\beta$ expression in macrophage cells increased in the treatment group compared to the control group. Increased TGF- $\beta$ expression was higher in the Citrus limon $L$ peel oil treatment, not only after three days but also after five days. TGF- $\beta$ is important in angiogenesis, reepithelialisation and tissue regeneration. In this study, the administration of Citrus limon $L$ peel oil containing limonene was shown to be capable of accelerating the process of traumatic ulcer healing in subjects suffering from diabetes mellitus. This is because the limonene content of the oil can inhibit the production of TNF- $\alpha, \mathrm{IL}-1 \beta$ and IL-6 [24], and increase the expression of TGF- $\beta$, thereby enabling the ulcer healing process to progress to the subsequent proliferative phase, the role of TGF- $\beta$ in which is important [19].

The potent antibacterial and antifungal effects of Citrus limon $L$ peel oil may also prevent suspected secondary infection in traumatic ulcers. As an antibacterial, the oil may accumulate in bacterial cell membranes, alter the composition of fatty acids in the bacterial cell membrane and induce leakage by proton motive force. As antifungal agents, the terpenoids in Citrus limon $L$ peel oil may inhibit ergosterol 
production, in turn, affecting the permeability of the fungus and inhibiting its growth [25].

\section{CONCLUSION}

Topically-treated Citrus limon $L$ peel oil stimulates TGF- $\beta$ expression and macrophage numbers in traumatic ulcer healing in diabetic conditions after three and seven days. Treatment with Citrus limon $L$ peel oil has therapeutic potential for the treatment of diabetes-induced traumatic ulcers.

\section{DECLARATIONS}

\section{Acknowledgement}

This study was funded by Faculty of Dental Medicine, Universitas Airlangga, Surabaya, Indonesia (no. 2187/UN3.1.2/LT/2018).

\section{Conflict of interest}

The authors declare that no conflict of interest is associated with this work.

\section{Contribution of authors}

We declare that the research described in this article was undertaken by its named authors who are responsible for all liabilities resulting from any claims relating to its content.

\section{Open Access}

This is an Open Access article that uses a funding model which does not charge readers or their institutions for access and distributed under the terms of the Creative Commons Attribution License (http://creativecommons.org/licenses/by/ 4.0) and the Budapest Open Access Initiative (http://www.budapestopenaccessinitiative.org/rea d), which permit unrestricted use, distribution, and reproduction in any medium, provided the original work is properly credited.

\section{REFERENCES}

1. Mortazavi H, Safi $Y$, Baharvand M, Rahmani $S$. Diagnostic Features of Common Oral Ulcerative Lesions: An Updated Decision Tree. Int J Dent. 2016; 2016: 1-14.

2. Regezi J, Sciubba J, Jordan RC. Oral Pathology Clinical Pathologic Correlations. 7th ed. Oral Pathology Clinical Pathologic Correlations. St. Louise, Missouri: Elsevier Inc.; 2016. pp 1-496.
3. Al-Maskari AY, Al-Maskari MY, Al-Sudairy S. Oral Manifestations and Complications of Diabetes Mellitus. SQU Med J. 2011; 11: 179-86.

4. International Diabetes Federation. IDF Diabetes Atlas. 7th ed. International Diabetes Federation. Brussel: International Diabetes Federation; 2015; pp 1-136.

5. Bajaj S, Prasad S, Gupta A, Singh VB. Oral manifestations in type-2 diabetes and related complications. Indian J Endocrinol Metab. 2012; 16(5): 777-779.

6. Belenguer-Guallar I, Jiménez-Soriano $Y$, ClaramuntLozano A. Treatment of recurrent aphthous stomatitis. A literature review. J Clin Exp Dent. 2014; 6(2): 168-174.

7. Tarakji B, Gazal G, Ali Al-Maweri S, Nasser Azzeghaiby $S$, Alaizari N. Guideline for the diagnosis and treatment of recurrent aphthous stomatitis for dental practitioners. $J$ Int Oral Heal. 2015; 7(5): 74-80.

8. Makni M, Jemai R, Kriaa W, Chtourou Y, Fetoui H. Citrus limon from Tunisia: Phytochemical and Physicochemical Properties and Biological Activities. Biomed Res Int. 2018; 2018: 1-10.

9. Ahmed OM, Ashour M badr, Fahim HI, Ahmed NA. Citrus limon and Paradisi Fruit Peel Hydroethanolic Extracts Prevent the Progress of Complete Freund's AdjuvantInduced Arthritis in Male Wistar Rats. Adv Anim Vet Sci. 2018; 6(10): 443-55.

10. Yu L, Yan J, Sun $Z$. D-limonene exhibits anti@inflammatory and antioxidant properties in an ulcerative colitis rat model via regulation of iNOS, COX2 , PGE2 and ERK signaling pathways. Mol Med Rep. 2017;15: 2339-2346.

11. Pakyari M, Farrokhi A, Maharlooei MK, Ghahary $A$. Critical Role of Transforming Growth Factor Beta in Different Phases of Wound Healing. Adv Wound Care. 2013; 2(5): 215-224.

12. Academies NRC of TN. Guide for the care and use of laboratory animals. 8th Edn. Washington: The Nattional Academies Press; 2011. pp 1-209.

13. Radenković M, Stojanović M, Prostran M. Experimental diabetes induced by alloxan and streptozotocin: The current state of the art. J Pharmacol Toxicol Methods. 2015; 78: 13-31.

14. Ernawati DS, Puspa A. Expression of vascular endothelial growth factor and matrix metalloproteinase-9 in Apis mellifera Lawang propolis extract gel-treated traumatic ulcers in diabetic rats. Vet World. 2018; 11(3): 304-309.

15. Rahayu RP, Prasetyo RA, Purwanto DA, Kresnoadi U, Iskandar RPD, Rubianto $M$. The immunomodulatory effect of green tea (Camellia sinensis) leaves extract on immunocompromised Wistar rats infected by Candida albicans. Vet World. 2018; 11: 765-770.

16. Prabajati R, Hernawan I, Hendarti HT. Effects of citrus limon essential oil (Citrus limon L.) on cytomorphometric changes of Candida albicans. Dent J (Majalah Kedokt Gigi). 2017;50(1):43.

17. Hsouna A Ben, Halima N Ben, Smaoui S, Hamdi $N$. Citrus lemon essential oil: chemical composition, 
antioxidant and antimicrobial activities with its preservative effect against Listeria monocytogenes inoculated in minced beef meat. Lipids Health Dis. 2017; 16(1): 146.

18. Politis C, Schoenaers J, Jacobs R, Agbaje JO. Wound healing problems in the mouth. Front Physiol. 2016; 7 : 1-13.

19. Barrientos S, Stojadinovic O, Golinko MS, Brem $H$, Tomic-Canic M. Growth factors and cytokines in wound healing Stephan. Wound Rep Reg. 2008;16:585-601.

20. DeClue CE, Shornick LP. The cytokine milieu of diabetic wounds. Diabetes Manag. 2015; 5(6): 525-537.

21. Surboyo MDC, Ernawati DS, Arundina I, Rahayu RP. Oral Ulcer Healing after Treatment with Distilled Liquid Smoke of Coconut Shell on Diabetic Rats. J Krishna Inst Med Sci Univ 2019; 8(2): 70-79.
22. Brizeno LAC, Assreuy AMS, Alves APN., Sousa FB, Silva $P G$ de $B$, Sousa SCOM de, et al. Delayed healing of oral mucosa in a diabetic rat model Implication of TNF$\alpha, I L-1 \beta$ and FGF-2. Life Sci 2016; 155: 36-47.

23. Miguel MG. Antioxidant and anti-inflammatory activities of essential oils: A short review. Molecules 2010; 15(12): 9252-9287.

24. Kummer $R$, Fachini-Queiroz FC, Estevão-Silva CF, Grespan R, Silva EL, Bersani-Amado CA, et al. Evaluation of anti-inflammatory activity of citrus latifolia Tanaka essential oil and limonene in experimental mouse models. Evidence-based Complement Altern Med 2013; 2013: 1-8.

25. Hernawan I, Radhitia D, Hadi P, Ernawati DS. Fungal Inhibitory Effect of Citrus limon Peel Essential Oil on Candida albicans. Dent J 2015; 48(2): 84-88. 